during an average period of 20 days. The protein supply was reduced according to three different modalities :

(1) Diets $22(0)$ and $18(0)$, cereals (barley, wheat, maize) - soyabean meal non supplemented with lysine, without milk powder.

(2) Diets $22(15)$ and $18(10)$ including 15 and 10 p. 100 milk powder, respectively allowing a 30 p. 100 reduction of the soyabean meal.

(3) Diets $22(+)$ and $18(+)$ corresponding to a supplementation of diets $22(0)$ and $18(0)$ supplying the same amount of lysine as diets $22(15)$ and $18(10)$, respectively.

During the second age (up to $25 \mathrm{~kg}$ live weight within the same litter) diet 22 (0) including 22 p. 100 protein and 1.2 p. 100 lysine was offered ad libitum. After transfer to the fattening house pigs were fed according to a progressive restriction plan a standard diet including $17 \mathrm{p} .100$ protein and 0.85 p. 100 lysine. The animals were slaughtered at $101.4( \pm 2.3 \mathrm{~kg})$ live weight on an average and the lean percentage of the carcasses was estimated on the basis of linear measurements. During the 1 stage period, reduction of the protein level led to a significant decrease in the weight gain, i.e., 25 and 15 p. 100 , respectively with treatments (1) and (2). Conversely, the weight gain increased by 14 and $33 \mathrm{p} .100$ when incorporating 15 and $10 \mathrm{p} .100$ milk powder to the weaning diet including 22 and 18 p. 100 protein, respectively. The effects of lysine supplementation (treatment 3) were not significant whatever the protein level of the diet. When leaving the post-weaning house, reduction of the protein level in the initial diet led to a significant decrease in the piglet weight, i.e., 1.15 and $1.55 \mathrm{~kg}$, respectively with treatments (1) and (2). At this stage a $1.15 \mathrm{~kg}$ increase in the live weight was due to the incorporation of milk powder in the weaning diet including 22 p. 100 proteins. The advantage of diet 22 (15) was maintained until slaughter resulting in significant reductions of the production length, i.e., 3.6 days as compared to diet $22(0)$ and 6.1 days as compared to diet $18(0)$. The carcass yields (p. 100 of the live weight) and lean yields (p. 100 of the carcass weight) were not affected by the characteristics of the weaning diet. In these experimental conditions, use of milk powder would be advantageous at an approximate minimum price of $7.25 \mathrm{~F} / \mathrm{kg}$ as compared to that of soyabean meal and cereals $(2.50 \mathrm{~F} / \mathrm{kg}$ and $1.40 \mathrm{~F} / \mathrm{kg}$, respectively). Our results compared to other data suggest that it is not advisable to lower the protein level of the weaning diet for piglets without maintaining a very high protein quality. Accordingly, use of proteins rich in essential amino acids is undoubtedly better than a mere supplementation of soyabean meal.

\title{
Amino acid digestibility : use of the ileo-rectal shunt technique in pigs
}

\author{
M. PICARD, Solange BERTRAND, F. GENIN, R. MAILLARD \\ A.E.C., Service Développement Alimentation animale, 03600 Commentry \\ France
}

The surgical procedure described in this paper was used to collect digesta from the distal small intestine without any cannulation. The terminal ileum was cut and fitted to the side of the descending colon just before the rectum (Fuller \& Livinstone, 1983). The ileal juices were obtained from the anus. Growing pigs of $20 \mathrm{~kg}$ live weight recovered very well after the operation and could be used for several months. The amino acid digestibility data obtained are in keeping with those derived from classical methods (ileocaecal re-entrant cannulas). 